\title{
Technology Readiness of the NEXT Ion Propulsion System
}

\author{
Scott W. Benson \\ NASA Glenn Research Center \\ 21000 Brookpark Road \\ Cleveland, OH 44135 \\ 216-977-7085 \\ Scott.W.Benson@nasa.gov \\ Michael J. Patterson \\ NASA Glenn Research Center \\ 21000 Brookpark Road \\ Cleveland, OH 44135 \\ 216-977-7481 \\ Michael.J.Patterson@nasa.gov
}

Abstract-The NASA's Evolutionary Xenon Thruster (NEXT) ion propulsion system has been in advanced technology development under the NASA In-Space Propulsion Technology project. The highest fidelity hardware planned has now been completed by the government/industry team, including: a flight prototype model (PM) thruster, an engineering model (EM) power processing unit, EM propellant management assemblies, a breadboard gimbal, and control unit simulators. Subsystem and system level technology validation testing is in progress. To achieve the objective Technology Readiness Level 6, environmental testing is being conducted to qualification levels in ground facilities simulating the space environment. Additional tests have been conducted to characterize the performance range and life capability of the NEXT thruster. This paper presents the status and results of technology validation testing accomplished to date, the validated subsystem and system capabilities, and the plans for completion of this phase of NEXT development. The next round of competed planetary science mission announcements of opportunity, and directed mission decisions, are anticipated to occur in 2008 and 2009. Progress to date, and the success of on-going technology validation, indicate that the NEXT ion propulsion system will be a primary candidate for mission consideration in these upcoming opportunities. ${ }^{12}$

\section{TABLE OF CONTENTS}

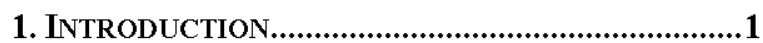

2. THE NEXT SYSTEM ..............................................2

3. NEXT TECHNOLOGY VALIDATION........................3

4. CoNCLUSIONS ………………………............................

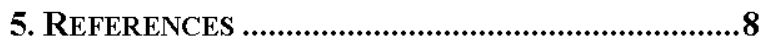

6. BIOGRAPHIES …………………………………............10

${ }^{1}$ U.S. Government work not protected by U.S. copyright.

${ }^{2}$ IEEEAC paper \#1479, Version2, Posted December 13, 2007.

\section{INTRODUCTION}

NEXT as an integrated technology project is comprised of the development of an advanced xenon ion thruster, a power processor unit, xenon feed system, a gimbal, and the control algorithms for system operation [1]. The NEXT project phase 2 develops flight-like engineering model components, with sufficient performance, functional, environmental and integration testing, with life analysis and test, to validate the technology approach and hardware design. The NEXT team is composed of NASA Glenn Research Center (GRC), the Jet Propulsion Laboratory (JPL), Aerojet General Corp. and L-3 Communications Electron Technologies Inc. The NEXT project is being conducted under the NASA Science Mission Directorate In-Space Propulsion Technology (ISPT) project, which is managed by the Glenn Research Center.

NEXT is an advanced ion propulsion system oriented towards robotic exploration of the solar system using solar electric power. Potential mission destinations that could benefit from a NEXT Solar Electric Propulsion (SEP) system include inner planets, small bodies, as well as outer planets and their moons when chemical or aerocapture approaches are used to capture at the destination body. This range of robotic exploration missions generally calls for ion propulsion systems with deep throttling capability and system input power ranging from 5 to $25 \mathrm{~kW}$, as referenced to solar array output at 1 Astronomical Unit (AU).

The selection process for NASA robotic science missions can be characterized as highly competitive, whether selected through a directed process or formal competition. A proposal implementing advanced technologies for a future mission can make or break the mission concept. In some concepts, a technology may enable the fundamental science breakthrough; in others, the technology may be considered too risky to implement within the mission budget and schedule constraints. It is therefore imperative that 
advanced technologies are well characterized prior to full consideration for a mission. That characterization consists of analyses and testing to demonstrate system level validation in relevant environments, or Technology Readiness Level 6 (TRL6). Past NASA Discovery, Mars Scout and New Frontiers Announcements of Opportunity, [2], [3] and [4], have dictated that TRL 6 be demonstrated by the Confirmation Review at the end of the project Phase B, and that the path to accomplish such be fully described in the mission proposal. This paper presents the status and results of technology validation testing accomplished to date, the validated subsystem and system capabilities, and the plans for completion of this phase of NEXT development.

The state-of-art (SOA) in ion propulsion for solar system exploration missions is the NASA Solar Electric Propulsion Technology Application Readiness (NSTAR) ion propulsion system. NSTAR underwent a technology development process, similar to NEXT, in the 1990's. It was demonstrated on the New Millenium Program Deep Space 1 mission, propelling the spacecraft to the asteroid Braille and comet Borrelly. NSTAR was proposed for use on the Dawn mission to the main belt asteroids Vesta and Ceres under the NASA Discovery mission program. Dawn was launched in September 2007; the NSTAR ion propulsion system was successfully checked out, and the spacecraft is on the way to Vesta.

\section{THE NEXT SYSTEM}

The NEXT project products, in a representative system configuration illustrated in Figure 1, consist of a prototype model (PM) ion thruster, an engineering model (EM) Power Processing Unit (PPU), EM xenon feed system High Pressure Assembly (HPA) and Low Pressure Assemblies (LPA), a breadboard gimbal and a Digital Control Interface Unit (DCIU) Simulator that is comprised of EM-level HPA and LPA control cards and system control algorithms.

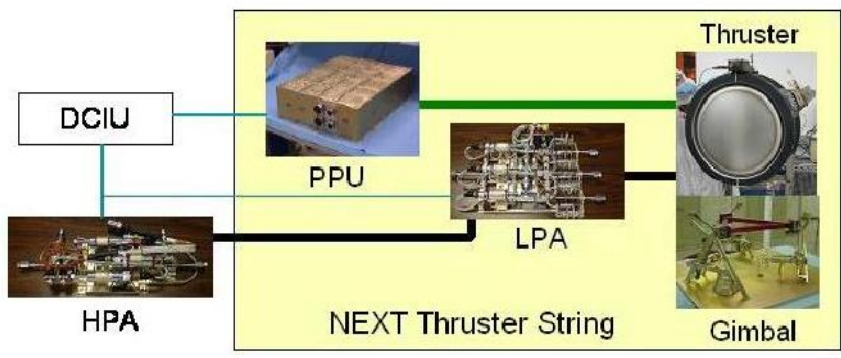

Figure 1 - NEXT ion propulsion system elements

This design approach was selected to provide future NASA science missions with the greatest value in mission performance benefit at a low total development cost. The NEXT thruster and other component technologies represent a significant advancement in technology beyond the SOA
NSTAR thruster systems [5]. NEXT performance exceeds single or multiple NSTAR thrusters over most of the thruster input power range. Higher efficiency and specific impulse, and lower specific mass reduce the wet propulsion system mass and parts count. The NEXT thruster xenon propellant throughput capability is more than twice that of NSTAR, so fewer thrusters are needed. The NEXT power processor and propellant feed system technologies provide mass and performance benefits versus NSTAR. Comparisons of NEXT and state-of-the-art (SOA) NSTAR performance characteristics are listed in Table 1.

Table 1 - Performance Characteristics of NEXT vs. NSTAR SOA.

\begin{tabular}{|l|c|c|}
\hline \multicolumn{1}{|c|}{ Characteristic } & NEXT & $\begin{array}{c}\text { NSTAR } \\
\text { SOA }\end{array}$ \\
\hline Thruster Power Range, $\mathrm{kW}$ & $0.5-6.9$ & $0.5-2.3$ \\
\hline Max. Specific Impulse, $\mathrm{sec}$ & $>4100$ & $>3100$ \\
\hline Max. Thrust, $\mathrm{mN}$ & 236 & 92 \\
\hline Max. Thruster Efficiency & $>70 \%$ & $>61 \%$ \\
\hline Max, PPU Efficiency & $95 \%$ & $92 \%$ \\
\hline PPU Specific Mass, kg/kW & 4.8 & 6.0 \\
\hline PMS Single-String Mass, $\mathrm{kg}$ & 5.0 & 11.4 \\
\hline $\begin{array}{l}\text { PMS Unusable Propellant } \\
\text { Residual }\end{array}$ & $1.00 \%$ & $2.40 \%$ \\
\hline
\end{tabular}

The NEXT IPS development project has also placed particular emphasis on key aspects of IPS development with the intention of avoiding the difficulties experienced by the Dawn mission in transitioning the NSTAR-based technology to an operational ion propulsion system [6] and [7]. NEXT technology is applicable to a wide range of NASA solar system exploration missions (see Fig. 2), as well as earth-space commercial and other missions of national interest. NEXT affords larger delivered payloads and smaller launch vehicle size for Discovery [8], New Frontiers [9], Mars Exploration [10], and Flagship outerplanet exploration missions [11].

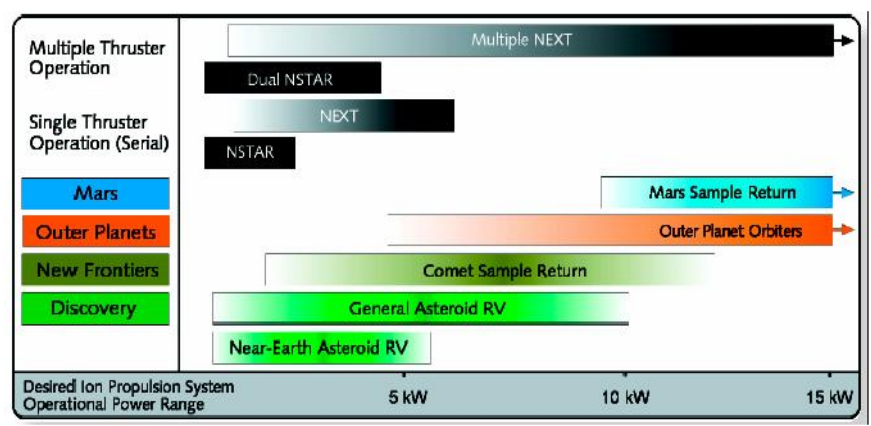

Figure 2 - NEXT is applicable to a broad range of mission classes. 


\section{NEXT TECHNOLOGY VALIDATION}

The NEXT subsystems were developed under requirements specified at the ISPT project level, and the NEXT project level flow-down requirements that resulted. Project validation activities, including tests, inspections and analyses, are performed against these requirements. The following sections summarize the validation status and completion plans at the subsystem and system level. The detailed results of validation analyses and tests are described in referenced documents.

\section{Ion Thruster}

The NEXT thruster is a $0.54-6.9 \mathrm{~kW}$ input power, $36 \mathrm{~cm}$ beam diameter, xenon ion thruster with 2 -grid ion optics. The beam current at full power of $6.9 \mathrm{~kW}$ is $3.52 \mathrm{~A}$. It has a maximum specific impulse of greater than 4170 seconds at a maximum thrust of greater than $236 \mathrm{mN}$, with peak efficiency in excess of $70 \%$. The xenon throughput project requirement is $>300 \mathrm{~kg}\left(1.23 \times 10^{7} \mathrm{Ns}\right.$ total impulse $)$, with a $450 \mathrm{~kg}$ qualification level. The analysis-based capability of the thruster is $>730 \mathrm{~kg}$.

Five engineering model (EM) thrusters have been manufactured at GRC and tested. During Phase 1 of the NEXT project (ending in August 2003) EM thruster testing included detailed performance evaluations [12], a 2000 hour wear test at full power [13], integration testing with a breadboard PPU and breadboard PMS [14] and structural tests to characterize thruster dynamic behavior for further thruster development. During Phase 2 to date, EM thruster performance has been tested in a multi-thruster array, and a long-duration life test of an EM thruster has accumulated more than 13,200 hours of operation at high power.

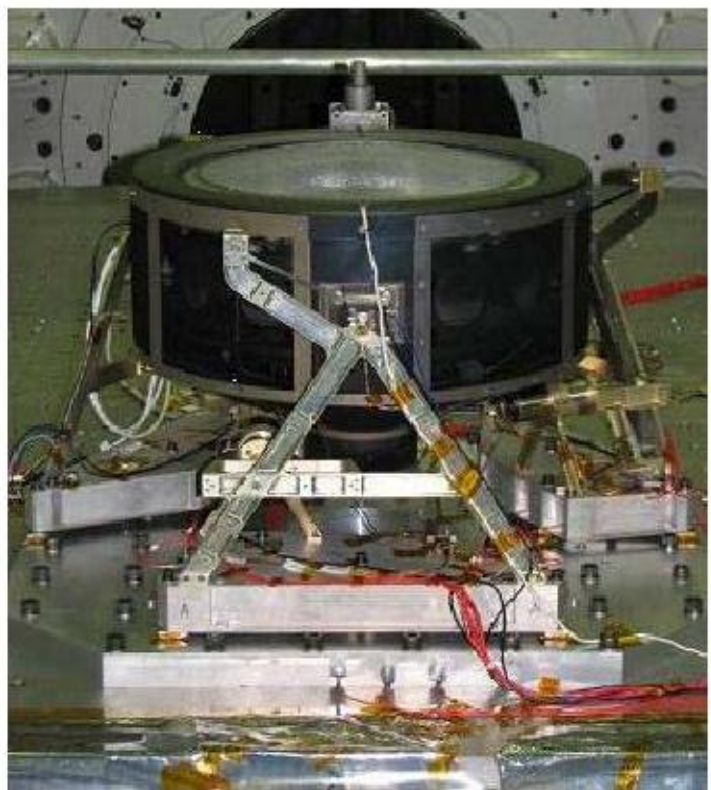

Figure 3 - PM thruster/gimbal assembly in vibration test preparations.
Also during Phase 2 the first prototype model (PM) thruster was manufactured by Aerojet and delivered to GRC. Acceptance testing of the thruster was completed at GRC [15] and the performance was found to be consistent with that demonstrated from multiple EM thrusters [16]. The PM thruster was subsequently subjected to a series of validation tests at JPL including: thruster/gimbal functional tests, a thermal development test, and qualification-level environmental (vibration and thermal vacuum) tests. The thermal development test [17] proceeding environmental tests was performed to develop and validate the thruster thermal model [18] and demonstrate thruster operation and temperature margins over a large temperature range. The vibration test [19], shown in Figure 3, was conducted with the PM thruster integrated with the gimbal; conditions were $10.0 \mathrm{G}_{\mathrm{ms}}$, through each of the 3 axes for 2 -minute duration. The thruster performance was nominal pre- and postvibration. Although the testing was largely successful, several issues were identified including the fragmentation of potting cement on the discharge and neutralizer cathode heater terminations. This issue did not constrain completion of the vibration test, but resulted in some thruster rework, described later.

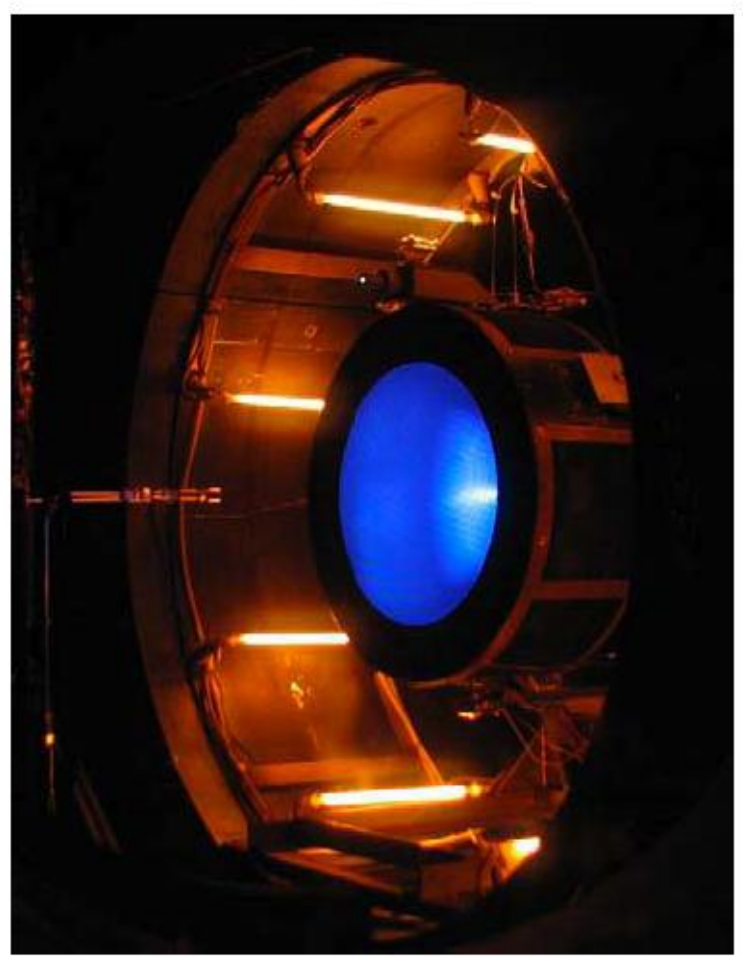

Figure 4 - PM thruster in thermal vacuum testing.

Thermal vacuum testing of the PM thruster [19], shown in Figure 4, was conducted using flight-approved methods and the Dawn spacecraft environmental requirements and test procedures. Test parameters included $-120^{\circ} \mathrm{C}$ cold and $+203^{\circ} \mathrm{C}$ hot limits, and 3 cycles with hot and cold dwells, with hot and cold thruster starts. Testing was truncated 
during the $3^{\text {rd }}$ cold cycle due to minor damage incurred during prior vibration testing. Functional testing of the thruster was subsequently completed with all data nominal.

The project team addressed the environmental test findings with minor design revisions and rework of the thruster. The rework of the PM1 thruster (PM1R) was successfully completed. The PM1R then underwent a repeat test sequence of performance acceptance, vibration and thermal/vacuum tests. [20] The only change to test parameters was to raise the thermal/vacuum hot limit to $215^{\circ} \mathrm{C}$ to accommodate minor changes in the thruster plasma screen. The repeat test sequence was fully successful. Performance acceptance test results matched the initial PM1 results. Vibration tests were without issue. The full three thermal cycles, with 24 hours of accumulated hot bias time, was completed in the thermal/vacuum test. Throughout the test sequence, thruster performance was repeatable and met requirements. The repeat test sequence validated the design modifications and completed the development of the NEXT thruster to TRL 5.

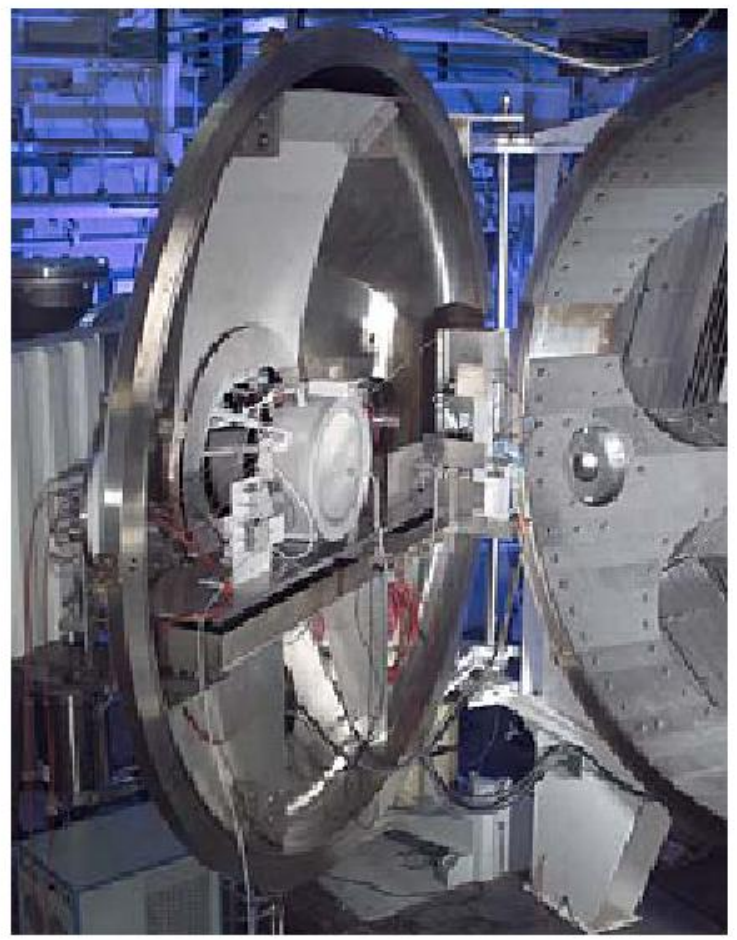

\section{Figure 5-NEXT thruster long duration test set-up in vacuum facility 16 at NASA GRC.}

Manufacturing of components for a second PM thruster has been completed at Aerojet and are available for assembly in support of first-user needs. Thruster documentation (work instructions and drawings) have been updated through the contractor release process to support assembly of the second PM thruster [21].

The life capability of the PM thruster will be established by a combination of a) results from the on-going EM thruster life testing, b) similarity analysis to the EM thruster, c) thruster service life modeling, d) thruster component life tests, and d) a full-power wear test of a PM thruster. An EM thruster successfully completed a 2000 -hour wear test in Phase 1 [13]. A second EM thruster (with PM ion optics manufactured by Aerojet) is presently undergoing long duration life testing at GRC [22] at full power having accumulated over 13,200 hours of operation to date, processing over $271 \mathrm{~kg}$ of xenon. The thruster has demonstrated over $1.11 \times 10^{7} \mathrm{~N}-\mathrm{s}$ total impulse. The throughput and total impulse are the highest ever demonstrated by an ion thruster in the history of space propulsion. The EM thruster performance and wear rates of critical thruster components are consistent with model predictions. The long duration test has begun operations at other thruster throttle points to begin collecting wear data to incorporate into life analyses. The EM3 long duration test set-up is shown in Figure 5, taken prior to test initiation in June 2005.

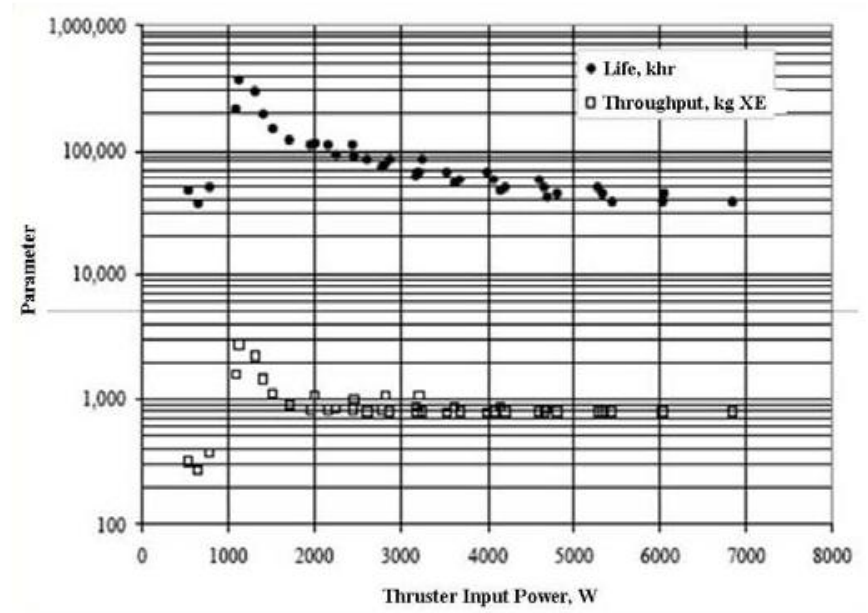

Figure 6 - Projected NEXT thruster life and propellant throughput versus NEXT thruster input power from the NEXT throttle table.

A service life assessment of the NEXT thruster was conducted at GRC for a number of throttle conditions [23]. The assessment involved the application of several models to evaluate all the known failure modes. Thruster lifetime, in hours of operation and xenon throughput, is plotted against thruster power and specific impulse in Figures 6 and 7. For the conditions investigated, the assessment conservatively predicted that the earliest failure would be the accelerator grid, with wear-through occurring sometime after 35,000 hours of operation. At most throttle points, this would result in over $730 \mathrm{~kg}$ of xenon throughput. At low power levels, below $1 \mathrm{~kW}$, in the unlikely scenario of operating the thruster at low power for the entire mission, a lower throughput capability results, though operating duration remains comparable to other throttle points. Other failure modes were predicted to occur at a condition in excess of $800 \mathrm{~kg}$ thruster xenon throughput; well beyond 
the mission-derived lifetime requirement of $300 \mathrm{~kg}$ xenon throughput.

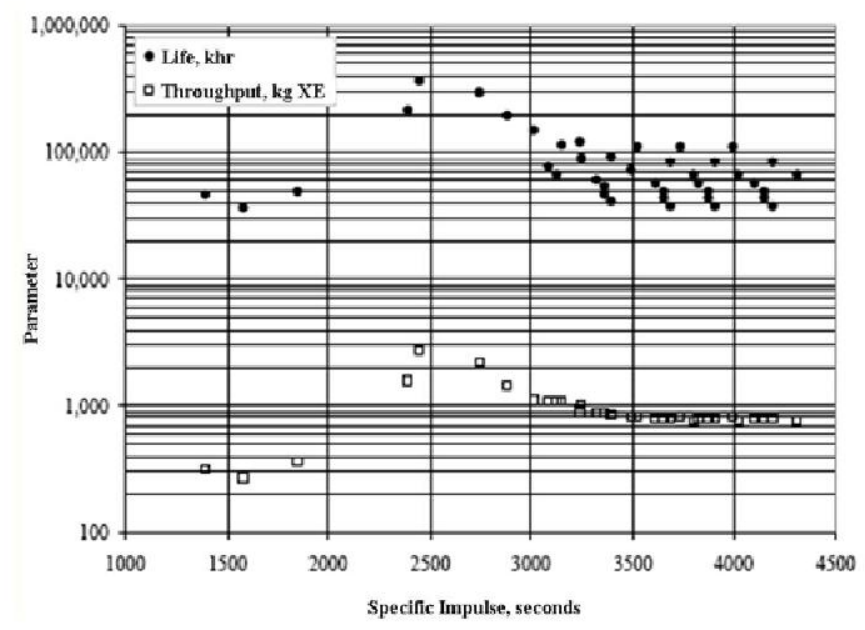

Figure 7 - Projected NEXT thruster life and propellant throughput versus NEXT thruster specific impulse from the NEXT throttle table.

Two component life tests will be performed by the NEXT project [24]. A high voltage propellant isolator (HVPI) life test was initiated in 2006 and has surpassed 14,600 hours under test conditions of $265^{\circ} \mathrm{C}, 2100 \mathrm{~V}$ and 32 torr inlet pressure. The test is being performed in the GRC Vacuum Facility 61, using two PM HVPIs provided by Aerojet. To date, HVPI leakage current is within specification; data trends do not indicate any concerns. Cathode heater life testing is imminent. The testing will be conducted on spare Aerojet PM thruster neutralizer and discharge cathode heaters in GRC Vacuum Facility 62.

After completion of system integration testing, described below, the project is planning to conduct a short duration wear test of the PM1R thruster. This test will enhance thruster life validation through: test of a flightrepresentative thruster built by the flight vendor, test of a thruster that has been through full environmental testing (two cycles), and providing wear trend data that can be directly correlated with the EM3 long duration test and life analyses.

Project resources are currently in place to continue thruster life validation test and analyses through fiscal year 2010 . This will provide ample opportunity to demonstrate thruster capability that far exceeds the values determined from mission analyses to date.

\section{Power Processing Unit}

The engineering model (EM) PPU was manufactured by L3 Communications ETI (L3) [25]. This was preceded by fabrication and successful integration test of breadboard PPU during Phase 1. After successful benchtop functional tests, the EM PPU was delivered to GRC for thruster integration testing. This test was predominantly successful, with the primary output supplies performing to expectations. A component failure within a low power output supply prevented full validation; this was accommodated with a ground supply to complete testing. The component failure resulted in redesign of the affected module, the EM PPU rework is due to be completed at the time of publication. The EM PPU will then be integrated into the single-string system integration test, described below and then subjected to qualification-level vibration and thermal vacuum testing. The EM PPU will then be available for a range of subsystem or system validation, including PPU EMI/EMC testing, system-level radiated EMI testing and PPU life testing integrated into a thruster life test.

The PPU, illustrated in Figure 8 , incorporates a modular beam power supply and improved packaging that provides performance and produce-ability benefits over the NSTAR PPU approach. It has a flexible, scalable architecture which can be adapted to a wide range of thrusters and missions, with a wide throttle range capability ( $250 \mathrm{~W}$ to $7200 \mathrm{~W}$ ), a $>0.2 \mathrm{~kW} / \mathrm{kg}$ specific power, and a simple thermal interface (a $65^{\circ} \mathrm{C}$ baseplate).

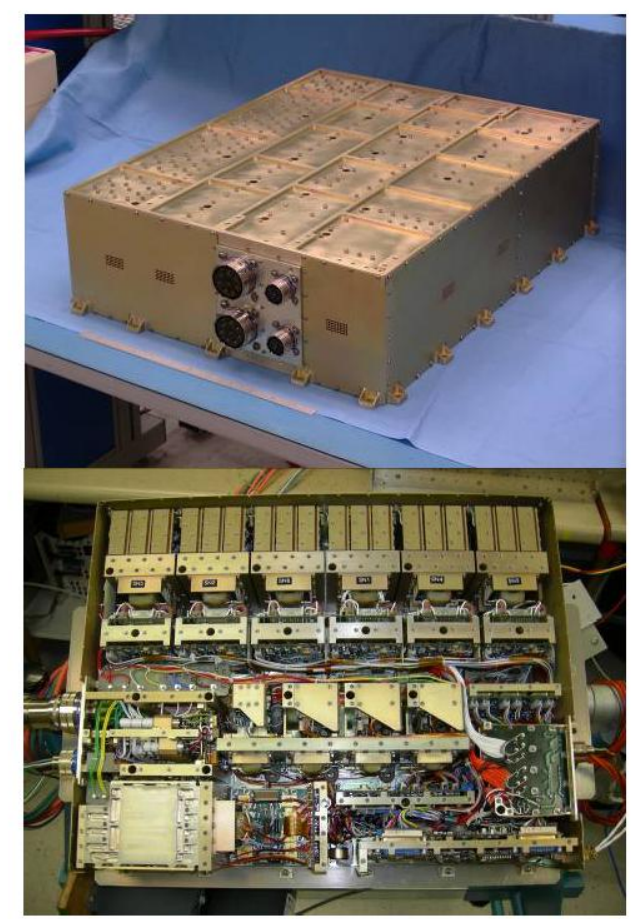

Figure 8 - NEXT EM Power Processing Unit

Additional design elements of the PPU include the following features described below. The PPU has modular construction designed for manufacturability and low cost. The input is designed for a wide range unregulated input bus $(80-160 \mathrm{Vdc})$, with separate $100 \mathrm{~V}$ and $28 \mathrm{~V}$ input filters. The balanced filters conform to JPL requirements (isolated return). The PPU has separate thruster outputs capable of operating either of two thrusters, one at a time. It also is 
designed to accommodate independent neutralizer keeper operation so that the PPU can operate the beam of one thruster combined with the neutralizer from a second thruster. The PPU has a built-in grid clear circuit with variable programmable duration and current capability up to the full output current of the discharge power supply.

\section{Propellant Management System}

The EM Propellant Management System (PMS) was manufactured by Aerojet [26]. The PMS delivers low pressure gas to the thruster from a supercritical xenon supply source, and it consists of a High Pressure Assembly (HPA) and a Low Pressure Assembly (LPA). The PMS provides independent xenon flow control to the thruster main discharge, and discharge and neutralizer cathodes. Xenon flow control is achieved by use of a thermal throttle flow control device (FCD) and a proportional flow control valve (PFCV). The FCD is a porous metal plug which provides a desired flow rate for a given inlet pressure and operating temperature. Fine control of flow rate is achieved by precise, active control of the FCD inlet pressure while the operating temperature of the porous metal plug is controlled at a constant setpoint. The inlet pressure and operating temperature of the FCD are actively controlled by the DCIU simulator. The inlet pressure is controlled using the PFCV with pressure transducer signal feedback while the operating temperature is controlled using a resistive element heater and temperature sensor feedback signal. This NEXT PMS design concept provides significant mass and volume reductions in the system as compared to the bangbang regulation scheme implemented for the Deep Space 1 and Dawn missions.

Aerojet has completed manufacturing of the EM PMS elements, including 2 HPAs (one flight-like) and 3 LPAs (one-flight like). The NEXT PMS LPA and HPA were flow-calibrated at the assembly level. Performance acceptance testing and calibration of each assembly were accomplished in initial functional testing. Required performance capabilities, including flow rate range and accuracy, were successfully achieved.

The PMS structural dynamic environment requirements were specified on the flight-like assemblies to most accurately represent the expected configuration and response. Requirements were developed by JPL to encompass the range of Delta II, Delta IV Medium, and Atlas 5 launch vehicles. Vibration testing of the flight-like HPA and LPA was performed at the Aerojet vibration test facility. A low-level sine sweep was performed before and after the random vibration test of each axis. Random vibration tests were performed to the $14.1 \mathrm{G}_{\mathrm{rms}}$ qualification level, with durations of 2 minutes at each axis.

The HPA and LPA vibration tests were completed successfully. First modes were greater than the $100 \mathrm{~Hz}$ required. Minor variations in first mode response, between random excitation and sine sweep testing results, were directly attributable to tie downs of the assembly harnesses to the test fixture.

Allowable PMS assembly flight temperatures, ranging from +27 to $+50{ }^{\circ} \mathrm{C}$, are driven by the qualification temperatures of critical flow control components. The HPA and LPA must be controlled within this range, regardless of environmental conditions. Thermal/vacuum testing of flight-like assemblies was conducted to qualification temperatures of +12 to $+70^{\circ} \mathrm{C}$ to validate successful design.

The PMS assembly thermal/vacuum testing was conducted at Vacuum Facility 12 at Aerojet. Functional tests (FT) were performed throughout the test sequence and consisted of: outlet pressure control for the HPA, and flow rates, accuracies, and rate change responsiveness for the LPA. In addition, the LPA was tested in a contingency flow control mode during functional testing during two of the temperature cycles. Control thermocouples were located at the assembly interface plate, representative of a spacecraft sense point.

The PMS thermal/vacuum tests were fully successful. The HPA and LPA retained flow control characteristics through cold and hot cycling. The test also demonstrated successful operation in a contingency mode over the full thermal range. The validation testing and analysis of the NEXT PMS has thus been completed.

\section{Digital Control Interface Unit Simulator}

The Digital Control Interface Unit (DCIU) is the primary interface between the spacecraft and the ion propulsion system [27]. It performs all the command and control functions for the PMS and the PPU. Under the scope of the NEXT program only DCIU simulators have been developed. The DCIU simulator consists of a computer, test support equipment, EM PMS pressure loop control cards, and the associated algorithms to control the PMS and PPU. The DCIU simulators are capable of operating a 3 thruster string system, and are being used to validate control algorithms, support PPU input/output testing and singlestring and multi-string integration tests, and operate a PMS kernel during thruster life testing. Fully integrating the DCIU functionality into the PPU is under consideration as an approach that may be implemented in a follow-on PPU build cycle. Elimination of the separate DCIU should reduce system cost and complexity.

\section{Gimbal}

JPL has completed the development of a breadboard gimbal for the NEXT thruster. Designed and fabricated by Swales Aerospace, the gimbal is of a flight-like design using JPLapproved materials and components. The mass of the gimbal is less than $6 \mathrm{~kg}$ (lighter than the Dawn gimbal used for the smaller NSTAR thruster), and has a two-axis range of motion: $\pm 19^{\circ}, \pm 17^{\circ}$. The gimbal has successfully 
completed integration and functional testing with the PM thruster, Figure 9, and has passed two qualification level vibration tests [28] and low-level shock tests, with minor issues. Few if any modifications are anticipated to transition to flight. However torque margin tests with the thruster harness and propellant line routing attached will be required.

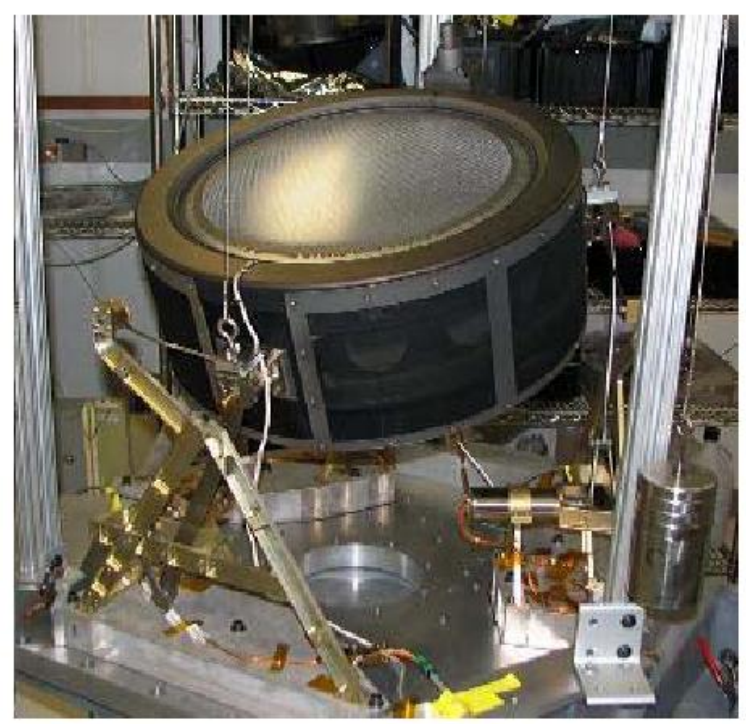

Figure 9 - NEXT gimbal during functional testing with the PM thruster.

\section{Integrated NEXT System}

The project has planned to perform three key integrated system tests; a multi-thruster interactions test, a single string system integration test with the most mature project products, and a multi-string system integration test operating up to three thrusters simultaneously. Additionally, plume/plasma modeling has been performed to allow analysis of future thruster configurations and characterization of environmental interactions with the spacecraft.

Multi-thruster Interactions Test-A multi-thruster interactions test was executed to evaluate two areas of system integration concerns; demonstrating that multiple thrusters perform together without degrading individual thruster performance or life, and understanding the plasma environment the spacecraft may be subjected to in single or multi-thruster operations. The test was performed at the GRC Vacuum Facility 6 in December 2005; three thruster operations are shown in Figure 10. The primary components of the test included: four EM thrusters mounted on a reconfigurable array, one of which was an instrumented non-operational unit, a gimbal simulator articulating one thruster, laboratory power supplies, laboratory xenon feed systems, extensive plume and plasma diagnostics, and a data acquisition and control system.

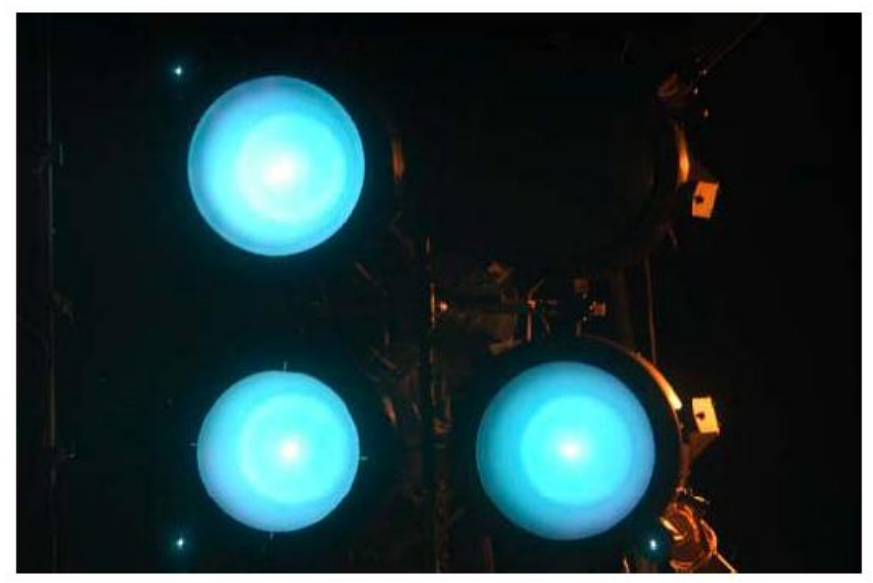

Figure 10 - Three NEXT EM thrusters operating during multi-thruster interaction testing.

Test objectives and sequences concentrated on engineering evaluation of thruster operations[29], plume characterization and interactions, with variation in thruster spacing and gimbaling effects considered[30], [31], neutralizer performance in multi-thruster arrays[32], and plasma environments around the thruster array and at the spacecraft interfaces[33]. Additionally, thermocouples were placed in various locations on the array to measure thermal interactions between operating and non-operating thrusters in support of thermal modeling.

The multi-thruster interactions test was fully successful, as reported in the references above, demonstrating:

multi-thruster performance is adequately predicted by superposition of multiple single thrusters,

- multi-thruster performance is not detectably affected by thruster spacing or gimbaling,

plasma environments at the spacecraft interface are mild,

neutralizer performance is not impacted by multithruster operations,

thruster operations were nominal with a single neutralizer operating with multiple thrusters, or thrusters operating in combination with neighboring thruster's neutralizer.

The data resulting from this test has been incorporated into thruster plume/plasma models developed by the SAIC Corporation under contract to JPL[34]. Analyses using this model confirm many of the demonstrated findings above. This model will allow NEXT system users to perform configuration specific analyses to assess system and spacecraft environments and interactions. 
Single-string System Integration Test-The NEXT project is now preparing to perform a single string system integration test to validate system level functional and performance requirements. System-level functionality was previously demonstrated with breadboard-level units in NEXT Phase 1 [35]. The primary components of this test include: the PM1R thruster, the EM PPU, flight-like EM HPA and LPA, the DCIU Simulator, diagnostics, and support equipment. The thruster, PPU, HPA, and LPA will be in a vacuum environment. The test will operate the system in its full range of operating modes, nominal and contingency, across the system throttle range. This test provides the primary opportunity to validate that the DCIU Simulator control algorithms and PMS control circuitry meet project requirements. In total, more than 100 systemlevel requirements will be validated through this test.

Multi-string System Integration Test-The project is also planning to perform a multi-string system integration test in fiscal year 2008. The objective of this test is to validate that the entire multi-string system functions nominally without interactions. The NEXT system test configuration would consist of the PM1R and two operational EM thrusters, a non-operating instrumented EM thruster, the EM PPU, the breadboard version of the PPU that was fabricated and tested in an earlier stage of the project, the flight-like HPA and LPA and two additional LPAs, and the DCIU Simulator. The third thruster will be powered by a laboratory power supply.

The single- and multi-string integration testing, with the subsequent EM PPU environmental tests, will complete the planned project activities towards validation of Technology Readiness Level 6. This validation will be formalized through project documentation and a formal system validation review. These are planned to be complete in fiscal year 2008, with thruster life validation continuing beyond.

\section{Conclusions}

The NEXT project has performed a thorough range of tests and analyses to validate Technology Readiness Level 6, and to verify that the products meet the project requirements. The tests have predominantly been very successful, with minor reworks required for some subsystems. Several key tests remain, with completion planned in 2008. TRL6 is a key milestone for introducing new technologies into NASA robotic science mission concepts. The NEXT project will have surpassed this milestone prior to initiation of the next rounds of competed mission Announcements of Opportunity, supporting full consideration in mission concept development and proposal.

\section{REFERENCES}

[1] Scott W. Benson, et.al., "NASA's Evolutionary Xenon Thruster (NEXT) Phase 2 Development Status," AIAA2005-4070, 41 Joint Propulsion Conference, July 2005.

[2] Announcement of Opportunity Discovery Program 2006 and Missions of Opportunity, NNH06ZDA001O, NASA, Washington, DC (Jan 2006).

[3] Announcement of Opportunity Mars Scout Program 2006 and Missions of Opportunity, NNH06ZDA002O, NASA, Washington, DC (May 2006).

[4] Announcement of Opportunity New Frontiers Program 2003 and Missions of Opportunity, AO 03-OSS-03, NASA, Washington, DC (Oct 2003).

[5] John R. Brophy, et al., "Ion Propulsion System (NSTAR) DS1 Technology Validation Report," JPL Publication 0010 , October 2000.

[6] John R. Brophy, "Preliminary Dawn IPS Lessons Learned," JPL, September 9, 2005.

[7] Michael J. Patterson, Scott W. Benson, "NEXT Ion Propulsion System Development Status and Performance," AIAA-2007-5199,43 ${ }^{\text {rd }}$ Joint Propulsion Conference, Cincinnati, OH July 2007.

[8] David Y. Oh, "Evaluation of Solar Electric Propulsion Technologies for Discovery Class Missions," AIAA2005-4270, 41st Joint Propulsion Conference, Tucson, AZ, July 2005 .

[9] Kevin E. Witzberger, et. al., "NASA's 2004 In-Space Propulsion Re-Focus Studies for New Frontiers Class Missions," AIAA-2005-4271, 41st Joint Propulsion Conference, Tucson, AZ, July, 2005.

[10] David Y. Oh, Scott W. Benson, Kevin E. Witzberger, and Michael Cupples, "Deep Space Mission Applications for NEXT: NASA's Evolutionary Xenon Thruster," AIAA-2004-3806, 40th Joint Propulsion Conference, Ft. Lauderdale, FL, July 2004.

[11] Scott W. Benson, John P. Riehl and Steven R. Oleson, "NEXT Ion Propulsion System Configurations and Performance for Saturn System Exploration," AIAA2007-5230, 43 $3^{\text {rd }}$ Joint Propulsion Conference, Cincinnati, $\mathrm{OH}$, July 2007.

[12] Soulas, G.C., Domonkos, M.T., and Patterson, M.J., "Performance Evaluation of the NEXT Ion Engine, AIAA-2003-5278, Joint Propulsion Conference, July 2003. 
[13] Soulas, G.C., et al., "NEXT Ion Engine 2000 Hour Wear Test Results," AIAA-2004-3791, 40 ${ }^{\text {th }}$ Joint Propulsion Conference, Ft. Lauderdale, FL, July 2004.

[14] Patterson, M.J., Pinero, L., Aadland, R., and Komm, D., "NEXT Ion Propulsion System: Single-String Integration Test Results," JANNAF Conference, May 2004.

[15] Daniel A. Herman, George C. Soulas and Michael J. Patterson, "Performance Evaluation of the PrototypeModel NEXT Ion Thruster," AIAA-2007-5212, 43 ${ }^{\text {rd }}$ Joint Propulsion Conference, Cincinnati, OH, July 2007.

[16] George C. Soulas and Michael J. Patterson, "NEXT Ion Thruster Performance Dispersion Analyses," AIAA-20075213, 43 ${ }^{\text {rd }}$ Joint Propulsion Conference, Cincinnati, OH, July 2007 .

[17] John R. Anderson, John S. Snyder, Jonathan L. Van Noord and George C. Soulas, "Thermal Development Test of the NEXT PM1 Ion Engine," AIAA-2007-5217, $43^{\text {rd }}$ Joint Propulsion Conference, Cincinnati, OH, July 2007.

[18] Jonathan L. Van Noord, "NEXT Ion Thruster Thermal Model," AIAA-2007-5218, 43 $3^{\text {rd }}$ Joint Propulsion Conference, Cincinnati, OH, July 2007.

[19] John S. Snyder, John R. Anderson, Jonathan L. Van Noord and George C. Soulas, "Environmental Testing of the NEXT PM1 Ion Engine," AIAA-2007-5275, 43 ${ }^{\text {rd }}$ Joint Propulsion Conference, Cincinnati, OH, July 2007.

[20] John S. Snyder, John R. Anderson, Jonathan L. Van Noord and George C. Soulas, "Environmental Testing of the NEXT PM1R Ion Engine," IEPC-2007-276, 30 International Electric Propulsion Conference, Florence, Italy, September, 2007.

[21] W. Andrew Hoskins, et. al., "NEXT Ion Propulsion System Production Readiness," AIAA-2007-5856, 43 ${ }^{\text {rd }}$ Joint Propulsion Conference, Cincinnati, OH, July 2007.

[22] Daniel A. Herman, George C. Soulas, and Michael J. Patterson, "NEXT Long-Duration Test after $11,570 \mathrm{~h}$ and $237 \mathrm{~kg}$ of Xenon Processed," IEPC-2007-033, 30 International Electric Propulsion Conference, Florence, Italy, September, 2007.

[23] Jonathan L. Van Noord, "Lifetime Assessment of the NEXT Ion Thruster," AIAA 2007-5274, 43 ${ }^{\text {rd }}$ Joint Propulsion Conference, Cincinnati, OH, July 2007.

[24] Luis R. Piñero, and James S. Sovey, "NEXT Thruster Component Verification Testing," AIAA-2007-5276, 43 $3^{\text {rd }}$ Joint Propulsion Conference, Cincinnati, OH, July 2007.
[25] Philip C. Todd, Robert Martinelli, Steven Wiseman, and Luis R. Piñero, "Status of the NEXT $7 \mathrm{~kW}$ Power Processing Unit," AIAA-2005-3868, 41st Joint Propulsion Conference, Tucson, AZ, July 2005.

[26] Randall S. Aadland, Hans Frederick, Scott W. Benson, and Shane P. Malone, "Development Results of the NEXT Propellant Management System," 54th JANNAF Propulsion Meeting, December 2005

[27] Jeffrey Monheiser, Randall S. Aadland, and Fred C. Wilson, "Development of a Ground Based Digital Control Interface Unit (DCIU) for the NEXT Propulsion System," AIAA-2004-41 12, 40 ${ }^{\text {th }}$ Joint Propulsion Conference, Ft Lauderdale, FL, July 2004.

[28] John S. Snyder, et. al., "Vibration Test of a Breadboard Gimbal for the NEXT Ion Engine," AIAA-2006-4665, $42^{\text {nd }}$ Joint Propulsion Conference, Sacramento, CA July 2006.

[29] Patterson, M.J., Foster, J., McEwen, H., Pencil, E., Van Noord, J., and Herman, D., NEXT Multi-Thruster Array Test - Engineering Demonstration, AIAA-2006-5180, Joint Propulsion Conference, (July 2006).

[30] Pencil, E.J., Foster, J.E., Patterson, M.J., Diaz, E., Van Noord, J., and McEwen, H., Ion Beam Characterization of NEXT Multi-Thruster Array Plume, AIAA-2006-5182, Joint Propulsion Conference, (July 2006).

[31] Foster, J.E., Pencil, E., Patterson, M.J., McEwen, H., Diaz, E., and Van Noord, J., Plasma Characteristics Measured in the Plume of a NEXT Multi-Thruster Array, AIAA-2006-5181, Joint Propulsion Conference, (July 2006).

[32] Foster, J.E., Pencil, E., McEwen, H., Patterson, M.J., Diaz, E., and Van Noord, J., Neutralizer Plasma Coupling in a NEXT Multi-thruster Array, AIAA-2006-5184, Joint Propulsion Conference, (July 2006).

[33] McEwen, H., Foster, J.E., Pencil, E., Patterson, M.J., Diaz, E., and Van Noord, J., Characterization of Plasma Flux Incident on a Multi-Thruster Array, AIAA-20065183, Joint Propulsion Conference, (July 2006).

[34] Mandell, M. J., Davis, V. A., NASA Evolutionary Xenon Thruster (NEXT) Multi-Thruster Array Test: Simulation and Analysis, SAIC Document 01-0011-085409, San Diego, CA, (Oct 2006)

[35] Michael J. Patterson, Luis R. Piñero, Randall. S. Aadland, R., and David Komm, "NEXT Ion Propulsion System: Single-String Integration Test Results," JANNAF Conference, May 2004. 


\section{BIOGRAPHIES}

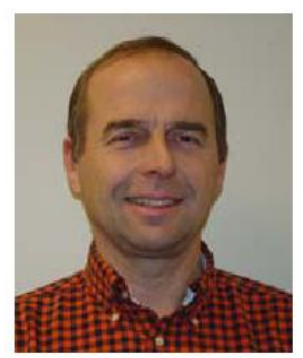

Scott Benson is the project manager of the NEXT ion propulsion system technology development project at NASA Glenn Research Center. He has been involved in electric propulsion development since 1997, including responsibility for delivery of the flight pulsed plasma thruster for the EO-1 spacecraft. Prior to coming to NASA Glenn, he previously served in the United States Air Force and worked in Centaur upper stage operations and payload integration for Shuttle and Titan at General Dynamics Space Systems Division. He has a BS and MS in Aerospace Engineering from Purdue and the Air Force Institute of Technology respectively.

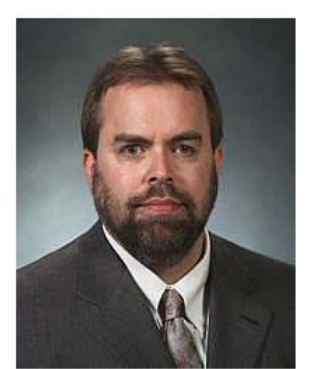

Michael Patterson is the Principal Investigator for the NEXT ion propulsion system technology project and the leader of the NASA Glenn Ion Propulsion Team. He was the design engineer for the NSTAR ion thruster successfully demonstrated on the Deep Space 1 mission, and the technical lead for cathode development for the International Space Station Plasma Contactor Unit. Michael received a BS in Physics from Wabash College and a MS in Physics from Colorado State University. 